\title{
a criança e a infância na escola: o que revelam os professores da rede municipal de caruaru - pe
}

\author{
iunaly felix de oliveira ${ }^{1}$ \\ universidade federal de Pernambuco, brasil \\ conceição gislane nóbrega lima de salles ${ }^{2}$ \\ universidade federal de Pernambuco, brasil
}

resumo

O presente texto se apresenta enquanto recorte de um conjunto de reflexões que compõem uma dissertação que se insere na discussão atual acerca do lugar dado às crianças e à infância, nos espaços destinados à educação Infantil no município de Caruaru - PE, a partir do entendimento dos discursos das professoras que trabalham no referido nível de ensino. Este trabalho teve como objetivo apreender os discursos atribuídos pelos professores da Educação Infantil em Caruaru à criança, à infância e à Educação Infantil, que têm subsidiado as formas de intervenção dos mesmos no espaço/tempo da Educação Infantil. Nesse contexto, delimitamos como nosso campo investigativo Centros Municipais de Educação Infantil da cidade de Caruaru- PE (CMEIS), nos quais foram contemplados 06 Centros Educacionais e entrevistados um total de 12 (doze) professores. Como procedimento metodológico, utilizamos entrevistas semiestruturadas e para análise dos dados nos apoiamos em aportes teórico-metodológicos da análise de discurso. Partimos do pressuposto de que, apesar das mudanças e do processo de ressignificação ocorridos nesse campo, inclusive em relação ao próprio entendimento que se tem de criança, de infância e de Educação Infantil, a escola das crianças/infância vem ainda assumindo uma vinculação com a infância que a insere em um tempo cronológico, associando-a ao futuro, a uma menoridade duvidosa. Do ponto de vista teórico, partimos da problematização da própria noção de infância e de Educação Infantil, seus significados e as implicações destes no campo da educação das crianças. Os discursos analisados, distribuídos em redes discursivas, em linhas gerais, apresentam enunciados e temporalidades para a infância, a criança e a Educação Infantil diversos, mas não excludentes. Embora em todos os discursos identifique-se uma ampliação da preocupação com o lugar da criança, da infância nas práticas da Educação Infantil, os mesmos revelam tanto indícios de permanência como de mudanças nas formas de dizer a criança, a infância e, consequentemente, a Educação Infantil. Os dados, portanto, expressam uma diversidade de sentidos e interpretações, mas indicam o quanto a escola e seus sujeitos ainda carecem de uma relação mais afirmativa com a criança e a infância.

palavras-chave: criança; educação infantil; infância; professores.

\section{child and childhood in school: what municipal teachers of caruaru-pe reveal}

abstract

This text is present as a snip of a set of reflexions that composes a dissertation that inserts itself in the current discussion around the place given to children and childhood in the

\footnotetext{
1 E-mail: iunaly@hotmail.com

2 E-mail: cgislane@terra.com.br
} 
space destined to childhood education in the city of Caruaru - PE, from the understanding of the teacher's discourses that work in that level of education. This work has as an objective to capture the discourses attributed by the teachers of Childhood Education to the children, to the childhood and to the Childhood Education, focusing on the discourses which have subsidized the teachers' forms of intervention in the space/time of Childhood Education. In this context, we have bound as our investigative field Municipal Centers of Childhood Education in the city of Caruaru - PE (CMEIS), from which it were contemplated 06 Educational Centers and interviewed a total of 12 (twelve) teachers. As a methodological procedure, we used semistructured interviews and for data analysis we supported ourselves in theoretical-methodological contributions of the discourse analysis. We start with the assumption that, despite the changes and the proccess of resignification ocurred in this field, including the own understanding of child, childhood and Childhood Education, the school of the children/childhood is assuming a link with the childhood that inserts it in a chronological time, associating it to the future, to a dubious minority. From a theoretical view, we start from the questioning of the very notion of childhood and Childhood Education, its meanings and the implications of those in the field of child education. The analyzed discourses, distributed in discoursive networks, generally speaking, present various statements and temporalities to the childhood, the child and the Childhood Education, but not excluding ones. Although in all the discourses is possible to identify an enlargement of the concern with tha place of the child, the childhood in the practices of Childhood Education, it shows evidences of permanence so as of changes in the form of discourse to the child, the childhood and, consequently, the Childhood Education. The data, therefore, express a diversity of meanings and interpretations, but indicates how much the school and its subjects still lack of a more assertive relationship with the child and the childhood.

keywords: child; childhood education; childhood; teachers.

\section{el niño y la infancia en la escuela: qué revelan los profesores de la red municipal de caruaru - pe}

resumen

El presente texto se presenta como el recorte de un conjunto de reflexiones que componen una disertación que se inserta en la actual discusión sobre el lugar dado a los niños y a la infancia, en los espacios destinados a la educación infantil en el municipio de Caruaru-PE, partiendo del entendimiento de los discursos de las profesoras que trabajan en dicho nivel de enseñanza. Este trabajo tuvo como objetivo conocer los discursos atribuidos por los profesores de la educación infantil en Caruaru al niño, a la infancia y a la educación infantil misma. En este contexto, hemos delimitado cómo nuestro campo investigativo los Centros Municipales de Educación Infantil de la ciudad de Caruaru-PE (CMEIS), donde fueron contemplados 6 Centros Educativos y entrevistados 12 (doce) profesores en total. Como procedimiento metodológico, utilizamos entrevistas semiestructuradas y para el análisis de los datos nos basamos en aportes teórico-metodológicos de análisis de discurso. Partimos del supuesto de que, a pesar de los cambios y del proceso de resignificación ocurridos en este campo, incluso en relación al entendimiento mismo que uno tiene de "niño", de "infancia" y de "educación infantil", la escuela de los niños/infancia todavía viene asumiendo una vinculación con la infancia que la pone en un tiempo cronológico, asociándola al futuro, a una minoridad dudosa. Desde el punto de vista teórico, partimos de la problematización de la noción misma de la infancia y de 
educación infantil, sus significados e implicaciones en el campo de la educación de los niños. Los discursos analizados, distribuidos en redes discursivas, en líneas generales, presentan enunciados y temporalidades diversos para la infancia, el niño y la educación infantil, pero no excluyentes. Aunque en todos los discursos se identifique una ampliación de la preocupación con el lugar del niño y de la infancia en las prácticas de educación infantil, se revelan tanto indicios de permanencia como de cambios en las formas de decir el niño, la infancia, y, consecuentemente, la educación infantil. Los datos, por lo tanto, expresan una diversidad de sentidos e interpretaciones, pero señalan en qué medida la escuela y sus sujetos todavía carecen de una relación más afirmativa con el niño y con la infancia.

palabras clave: niño; educación infantil; la infancia; profesores. 
a criança e a infância na escola: o que revelam os professores da rede municipal de caruaru - pe

Embora cada vez mais tenham se acentuado os questionamentos no campo da educação da infância e por mais que se observe uma vasta produção de estabelecimento de critérios, normas e disposições para o desenvolvimento da Educação Infantil, percebe-se que as concepções sobre criança, infância e Educação Infantil têm sido empregadas frequentemente como conceitos não avaliados.

Como apontam os estudos de Bezerra e Salles (2010, p. 6) acerca do modo como vêm sendo pensadas a criança e sua infância, "a escola infantil vem ainda assumindo uma vinculação com a ideia de um vir a ser adulto, implicada com uma noção de infância 'capturável', 'numerável', tecnicamente explicada pelo conjunto de saberes".

Buscamos nesse sentido, apreender o modo como doze professoras que atuam nas instituições públicas municipais da cidade de Caruaru - agreste pernambucano - concebem a criança, a infância e a Educação Infantil, o que consequentemente, tem subsidiado as formas de intervenção das mesmas no espaço/tempo da Educação Infantil ${ }^{3}$.

Partimos do pressuposto de que, apesar das mudanças e do processo de ressignificação ocorridos nesse campo, inclusive em relação ao próprio entendimento que se tem de criança, de infância e de Educação Infantil, a escola das crianças/infância vem ainda assumindo uma vinculação com a infância que a insere em um tempo cronológico, associando-a ao futuro, a uma menoridade duvidosa (KOHAN apud BEZERRA; SALLES, 2010).

Assumimos neste trabalho, a consideração das crianças como "sujeitos sociais e históricos marcados pelas contradições da sociedade em que vivemos. A criança não é filhote do homem, ser em maturação biológica; ela não se resume a

\footnotetext{
${ }^{3} \mathrm{O}$ presente artigo se apresenta enquanto recorte de uma dissertação de mestrado, defendida em 2013, cujo foco se dirige aos enunciados presentes nos discursos de professoras da rede municipal de ensino do município de Caruaru - PE, no que tange as concepções desses sujeitos acerca da criança, da infância e da própria Educação Infantil.
} 
ser alguém que não é, mas que se tornará (adulto, no dia em que deixar de ser criança)" (KRAMER, 1999, p. 272).

Quanto à infância, partimos da ideia que ela vai além de um período da vida humana, ou seja,

[...] que a experiência da infância não está vinculada unicamente à idade, à cronologia, a uma etapa psicológica ou a uma temporalidade linear, cumulativa e gradativa, já que ligada ao acontecimento, vincula-se à arte, à inventividade, ao intempestivo, ao ocasional, vinculando-se, portanto, a uma des-idade (ABRAMOWICZ; LEVCOVITZ; RODRIGUES, 2009, p. 195).

Assim sendo, a pergunta que norteia a presente discussão pode ser definida por: que enunciados compõem os discursos das professoras dos Centros Municipais de Educação Infantil em relação à criança, à infância e Educação Infantil? De forma geral pretendemos descrever e analisar os enunciados presentes nos discursos das professoras dos Centros Municipais de Educação Infantil em relação ao modo como concebem a criança, a infância e educação infantil.

Consideramos nesse estudo os enunciados como acontecimentos que emergem dos discursos e que estão ligados a outros enunciados e, "que nem a língua nem o sentido podem esgotar [...] porque é único como todo acontecimento, mas está aberto à repetição, à transformação, à reativação" (FOUCAULT, 2009, p. 31-32).

Tal investigação esteve fundamentada nos pressupostos teóricometodológicos da Análise de Discurso, inspirada nos estudos de Michel Foucault. Acreditamos nesse sentido que "analisar o discurso seria dar conta exatamente de relações históricas, de práticas muito concretas, que estão "vivas" nos discursos" (FISCHER, 2001, p. 198), ou seja, partindo dos discursos das professoras, foi possível perceber qual lugar da criança e da infância nas práticas cotidianas organizadas por essas profissionais e, ainda, como elas concebem o espaço da Educação Infantil, destacando a importância deste para as crianças atendidas.

Investigar os discursos das professoras de Educação Infantil apresenta-se como um desafio, pois é necessário trazer à tona o contexto em que cada profissional constrói seus enunciados, levando em conta suas vivências, 
experiências profissionais e pessoais e a interação com o meio sócio-cultural em que está inserido, que, no nosso caso, se refere às instituições em que atuam.

Estruturamos o presente texto trazendo inicialmente, as cartografias das discursividades em torno das crianças, das infâncias e da educação infantil, enfatizando como foram se constituindo os modos de falar, pensar e organizar esses enunciados, seguido do percurso metodológico adotado para empreendermos a tarefa de apreender os discursos das professoras. E, por fim, trazemos a discussão realizada a partir da descrição dos enunciados das professoras entrevistadas.

discursividades da infância: o dizer e o pensar sobre a criança, a infância e sua educação

Historicamente, têm-se inventado as mais diversas imagens e concepções da criança e da infância. As formações discursivas ${ }^{4}$ - que nesse caso se inserem no campo discursivo sócio-histórico - vêm sendo reelaboradas ao longo de períodos importantes, paralelamente a redefinições de conceitos como o de configuração familiar, organização social e projeto educativo.

É como afirma Corsino (2005, p. 204) “as formas de organização da sociedade e as condições de existência e de inserção da criança em cada contexto social, econômico, político e cultural é que vão delineando as diferentes concepções de infância e as diferentes formas de ser criança".

Podemos perceber com isso que a infância no sentido biológico, psicológico do termo sempre existiu, contudo, a sociedade nem sempre conferiu às crianças o mesmo lugar ou considerou suas especificidades. Em outras palavras, as crianças nem sempre foram vistas da mesma forma.

E é sobretudo no período da Idade Média e da Idade Moderna que os discursos em torno da criança, da infância, e do modo como essas devem ser

\footnotetext{
${ }^{4}$ Para isso, assumimos que "as formações discursivas definem objetos e conceitos do conhecimento como um campo e suas possíveis transformações, e não como entidades estáticas" (PORTO, 2008, p. 60).
} 
"educadas" vão se alterando, de forma que as configurações estabelecidas nessas periodizações, apresentam continuidades discursivas que ressoam até hoje.

De acordo com os estudos iconográficos de Ariès (2006) - representações através de imagens - pinturas, esculturas, etc. - a infância no período medieval não era retratada em sua imagem particular, sendo confundida com imagens de adultos em tamanho reduzido.

Ou seja, não se tinha um sentimento de infância. Sentimento esse "que não significa o mesmo que afeição pelas crianças: corresponde à consciência da particularidade infantil, essa particularidade que distingue essencialmente a criança do adulto, mesmo jovem" (ARIÈS, 2006, p.99), o que só aconteceria mais tarde, com o advento da Modernidade.

Ainda nesse período a imagem da criança equivalendo à pureza, à inocência, muito atrelada ao religioso, também foi retratada, imprimindo um discurso de criança como algo sagrado, quase que intocável, "inexistente". Esta imagem anedótica da infância se transformou numa fase leiga por volta dos séculos XV e XVI.

Tão logo a barreira da mortalidade infantil era vencida as crianças adentravam no mundo adulto, compartilhando as roupas, os costumes e até mesmo o exercício da profissão juntamente com os pais - teoria do homúnculo advogada pela psicologia onde as crianças eram vistas como adultos em miniatura - daí a afirmação de Ariès que o mundo pré-moderno não conheceu a infância.

Se na Idade Média as crianças estavam estritamente ligadas à sua família, sem participação, sem um lugar na organização social, ou mesmo sem suscitar interesse ou preocupação pela ausência de uma particularidade, por outro lado, na Modernidade essa responsabilidade passa a ser partilhada com o Estado, sobretudo pela escola, a qual irá na modernidade se apresentar como o dispositivo que irá se ocupar de produzir o processo de iniciação social da criança, bem como promover a passagem do estado da infância para o do adulto.

Tomando como base os estudos de Ariès (2006), que localiza no período Moderno a inauguração do que ele chama de "invenção da infância", outros 
estudiosos também refletem sobre essa "invenção", especialmente, a partir dos dois sentimentos que surgem em relação à infância: moralização e paparicação. Em outras palavras,

[...] de um lado, há a ideia de uma infância curta, até os 7 anos, quando ela é vista como uma distração para os adultos; de outro lado, a rejeição a essa "paparicação", em que um interesse de cunho psicológico e moral sustenta a ideia do prolongamento da infância, associada à criação dos colégios, onde as crianças, frágeis criaturas de Deus, ficariam separadas do mundo dos adultos de modo a serem preservadas e disciplinadas (KUHLMANN Jr.; FERNANDES, 2004, p. 21).

Temos a partir desses dois sentimentos, as bases para o entendimento da infância enquanto fase natural da vida (todos passam por ela), com particularidades e especificidades que as distinguem do mundo adulto. Enquanto a paparicação era observada junto às famílias das crianças, o sentimento que rejeitava essa ideia se fundamentava nos moralistas, educadores e eclesiásticos da época.

Esse segundo sentimento foi o responsável por um maior interesse dos adultos pelas crianças, marcando assim a distinção do mundo adulto em relação ao mundo infantil. E, dessa distinção, emergiu a necessidade de um espaço para proteger as crianças dos mistérios do mundo adulto e ao mesmo tempo preparálas para atuar nesse mundo. Institui-se assim a escola como espaço responsável pelo acontecimento da infância.

Ao instaurar esse lugar de "aluno" para as crianças, a modernidade passa a demonstrar um maior interesse dos adultos para com a infância, interesse sobre como se dá seu desenvolvimento, interesse em elaborar estratégias de resguardar a ingenuidade e a pureza infantis das crueldades e maldades da vida adulta, separando-as em lugares próprios, com vestimentas, brincadeiras e atividades específicas, pensadas para elas.

Essa noção escolarizada da infância, tão divulgada na modernidade, está presente ainda na atualidade traduzida nas práticas de muitas instituições de educação Infantil baseada, sobretudo nas duas configurações que surgem nos séculos XVII e XVIII.

$\mathrm{Na}$ primeira configuração, do século XVII, a infância é vista como negativa, que deve ser apressada para dar lugar ao homem adulto. Para 
Ghiraldelli Jr. (2000, p. 09 - 10) a escola é "um ambiente de formação e conformação" e a finalidade da educação nessa primeira configuração "é fazer com que a fase negativa da infância passe brevemente e possibilite ao homem surgir".

Podemos perceber a partir dessa configuração que a criança assume o lugar da invisibilidade, um "não lugar", em que suas necessidades e sua educação são decididas "de fora", por um adulto que dita o que cada criança vai aprender e como vai aprender.

No século XVIII, surge a outra configuração que se opõe à primeira. Nela o discurso acerca da infância se apresenta como fase positiva, a ser prolongada até a vida adulta.

Ainda segundo Ghiraldelli Jr. (2000, p. 10), nessa configuração “a infância é criatividade e pureza, e se a disciplina deve aparecer, deve vir como autonomia tirada de "dentro para fora'” e não imposta de fora para dentro como propõe a primeira configuração.

Assim a educação deve fazer com que a infância permaneça na vida adulta, "ou seja, que o homem (adulto) venha a materializar-se a partir do interior do homem (criança), mantendo em seu íntimo o verdadeiro humano que existia na criança" (Idem, p. 10). Nesse caso professor é como um companheiro nas descobertas da infância.

Essa configuração institui um lugar central para a criança na prática educativa, dando visibilidade a esse sujeito. Em outros termos, a educação parte dos interesses da criança, vem "de dentro", do autoconhecimento. Contudo, ambas as perspectivas ainda concentram nas mãos do professor, ou seja, do adulto, a direção do processo educativo.

Diferentemente dessa ideia de infância enquanto falta, exclusão, incapacidade, fragilidade, que aproxima as crianças da categoria dos que não têm, não sabem, assumimos no presente artigo uma posição que pense "a infância desde outra marca ou, melhor, a partir do que ela tem e não do que lhe falta: como 
presença e não como ausência; como afirmação e não como negação, como força e não como incapacidade" assim como nos propõe Kohan (2008, p. 41).

Inscrevemos por assim dizer, nossa investigação nessas proposições mais contemporâneas, pelo fato de que tais perspectivas nos revelam as bases de uma nova possibilidade para a Educação Infantil.

Reconhecendo a infância na sua especificidade e abandonando discursos que a vinculam a um tempo cronológico, as instituições de Educação Infantil começam a olhar para as crianças com outros olhares e a problematizar com maior intensidade suas ações. E tal como nos propõe Kohan (2003a, p. 248) a educação para as crianças pequenas deve permitir

[...] viver a infância como novidade, como experiência, como descontinuidade, como multiplicidade, como desequilíbrio, como busca de outros territórios, como história sempre nascente, como devir, como possibilidade de pensar o que não se pensa e de ser o que não se é, de estar em outro mundo daquele no qual se está. Se há algo a se preparar por meio da educação, é a não deixar a infância, a experiência.

A valorização dessa imagem mais afirmativa da criança é necessária para a compreensão de que "é por meio da produção e participação coletivas nas rotinas que as crianças tornam-se membros tanto de suas culturas de pares quanto do mundo adulto onde estão situadas" (CORSARO, 2011, p. 128).

Assim sendo, as experiências organizadas nos espaços da Educação Infantil podem ser mais significativas, ampliando as possibilidades de interação, autonomia e participação das crianças em atividades que estabelecem com seus pares (outras crianças da mesma idade ou não) e com os adultos que atuam na instituição.

Tal como demonstrado acima, a infância e a criança, sob um nome só, dizem, na verdade, de muitas infâncias e de muitas crianças. Estas vão desde uma visão mais unificadora - sobretudo quando nos reportamos à educação, quando se ensina ou quando se educa a criança e a infância -, até visões que, dentre essas múltiplas formas em que elas se apresentam, procuram resistir a certas pretensões unificadoras que acabam por totalizá-las. 


\section{situando o cenário da investigação}

A cidade de Caruaru conta com treze Centros Municipais de Educação Infantil (CMEI), sendo onze localizados no espaço urbano e dois no espaço rural, que juntos atendem 1690 crianças, distribuídos nas turmas de acordo com sua faixa etária; além de um quantitativo de profissionais (entre professores, auxiliares de sala e berçaristas) composto por 260 pessoas.

O nosso campo empírico é formado por cinco instituições que atendem crianças de zero a cinco anos e uma creche (crianças de até três anos), totalizando seis instituições. Os CMEI's estão localizados em diversos bairros da cidade e atendem, na maioria dos casos, a uma população com baixo poder aquisitivo.

Como procedimento inicial para a coleta dos dados, utilizamos um questionário com questões relativas ao tempo de atuação na educação, à escolha por trabalhar na Educação Infantil (EI), além de outras experiências profissionais vividas por essas professoras. Esse procedimento foi necessário para a escolha das professoras que efetivamente participariam da investigação, concedendo uma entrevista.

Sendo assim, compondo nosso corpus de análise, temos os discursos de doze professoras (entrevistando duas em cada CMEI) que atuam em diferentes instituições (seis CMEI's) de EI em Caruaru - PE, que nessa perspectiva denominamos como nossos sujeitos da enunciação. Os referidos discursos foram coletados a partir da realização de entrevistas semiestruturadas.

O uso das entrevistas semiestruturadas como estratégia de coleta e produção de dados representou para nós, a possibilidade da "captação imediata e corrente da informação desejada, praticamente com qualquer tipo de informante e sobre os mais variados tópicos" (LUDKE; ANDRÉ, 1986, p.34). Esse procedimento foi indispensável, uma vez que, ao não nos limitarmos a um roteiro fechado, pudemos aprofundar elementos durante a entrevista que careciam de maiores explicações.

A permanência em nosso campo empírico ocorreu entre os meses de maio e novembro de 2012, e os contatos para a realização das entrevistas foram 
agendados previamente, a fim de não atrapalhar as atividades cotidianas, bem como respeitando a disponibilidade de cada sujeito.

Adotamos a letra $\mathrm{P}$ seguida da numeração de 1 ao 12 para nos referirmos aos sujeitos, e para identificar as instituições atribuímos os caracteres A, B, C, D, E e F, a fim de mantermos em sigilo a identidade das mesmas.

No que se refere aos nossos sujeitos da enunciação, temos uma professora atuando no B - I (crianças de 2 anos) e duas no B - II (crianças de 3 anos), quatro professoras que atuam no pré - I (crianças de 4 anos) e cinco que trabalham no pré - II (crianças de 5 anos). Das doze professoras entrevistadas, apenas duas trabalham em tempo integral (professora P1 e P5), sendo que P1 atua na instituição em turmas diferentes (berçário - I pela manhã e pré - I à tarde).

Adotar um caminho a ser percorrido para responder as questões sobre como as professoras concebem a criança, a infância e a EI e sobre o lugar da criança e da infância nas práticas de EI no município de Caruaru, requer a escolha de uma opção teórico-metodológica que dê conta da complexidade de tal tarefa.

Encontramos na perspectiva da Análise do Discurso (AD) tal suporte. E nesta investigação, nos inspiramos, por assim dizer nas problematizações empreendidas por Michel Foucault. Em certa medida, fizemos o exercício de, assim como Fischer - estudiosa do autor -, mergulhar nos discursos e fazer emergir suas complexidades e multiplicidades.

Em seus estudos, a autora afirma que descrever enunciados

[...] significa apreender as coisas ditas como acontecimentos, como algo que irrompe num determinado tempo e espaço muito específicos, [...] esse feixe complexo de relações que 'faz' com que certas coisas possam ser ditas [...] num certo momento e lugar (FISCHER, 2003, p. 373).

Vale salientar que as proposições teórico-metodológicas da Análise do Discurso perpassaram toda a construção desta investigação, se fazendo presente desde o momento da escolha de nosso objeto, passando pelas discussões das discursividades que permeiam os estudos da criança, da infância e da Educação Infantil, até a realização das análises dos discursos das professoras entrevistadas.

Para apreendermos esses discursos e estabelecermos relações entre eles, estruturamos nosso material ordenando os enunciados em torno do que 
denominamos "redes discursivas". Tal organização se fez necessária, visto que os enunciados encontram-se dispersos, são heterogêneos e fazem parte de diferentes campos institucionais que lhes produzem.

Para fins deste artigo, optamos por trazer as discussões empreendidas acerca da rede discursiva "Noções de criança e infância construídas na experiência", que contempla os discursos de nossos sujeitos acerca de como vêm construindo ao longo de suas vivências junto com as crianças nos CMEI's, as noções de quem é essa criança e como se define sua infância.

o dizer e o pensar a criança e a infância no contexto da educação infantil: em cena os sujeitos da enunciação.

Para a discussão aqui empreendida, descrevemos os enunciados que configuram as noções das professoras acerca da criança e de sua infância, bem como destacamos os fatores que para elas são importantes para a vivência da infância.

Por essas delimitações vamos observar noções de criança que salientam sua inocência e sua pureza e que, por isso, reconhecem na infância a fase da vida em que ela precisa ser corrigida, preparada para viver no mundo adulto.

Ao mesmo tempo acompanhamos discursividades que privilegiam a criança enquanto sujeito que precisa ser ouvido, respeitado como criança. Nesse sentido, os enunciados vinculam-se menos a uma ideia de infância delimitada numa visão etapista e mais próxima da ideia de infância como uma condição que agrega especificidades.

A partir da análise dos discursos das professoras foi possível identificar a predominância da ideia de criança afirmada pela sua condição de ser da inocência, da pureza e que, por isso, precisa ser cuidado/protegido.

De igual forma, emergiu a noção da criança como sujeito imaturo, dependente das ações do adulto que, nesse caso, adquire a responsabilidade de "fazer passar" essa fase de imaturidade preparando as crianças para a vida futura. 
Partindo da discussão aqui empreendida, a infância emerge nesses discursos como a fase da vida em que é preciso aproveitar para se desenvolver, aprender. O discurso da professora P11 reflete essa concepção.

Infância é o tempo desse aprendizado, é a construção, é a base eu acho. Se você não plantar agora vai ser muito difícil você plantar depois, você pode até conseguir, mas o resultado no futuro não vai ser o mesmo (professora P11, entrevista realizada em 30 de novembro de 2012, grifos nosso).

O discurso de P11 sugere a concepção de criança baseada na ideia de devir em que a tenra idade é o momento mais importante para aprender, desse modo, é reforçada a noção da criança repleta de possibilidades, mas vazia e de certo modo "carente", ou seja, a ela é atribuída a condição de quem não sabe, e que por sua condição subalternizada em relação ao adulto, só chegará a saber se o outro (adulto) lhe ensinar.

Trata-se, então, de uma fase transitória cuja formação da criança se dará por meio da educação e da garantia do bem-estar físico desses sujeitos, ou seja, a infância é um período da vida que exige certos cuidados que deem suporte às necessidades específicas que cercam esse momento da vida.

Segundo Kohan (2003b, p. 4), essa negatividade que geralmente acompanha a constituição da noção de infância no âmbito educativo "significa que a criança pode ser alguma coisa no futuro e isto só faz sentido na medida em que ela ainda não é isso no presente. Estas são as duas formas prediletas de negar o que a infância é: afirmar seu ser em potência e sua ausência de ser em ato".

A rotina na Educação Infantil, com vistas ao atendimento dessas demandas que são decididas de fora, que privilegiam o "vir a ser" das crianças, busca o controle, a regulação, a disciplina dos corpos, da imaginação, da espontaneidade infantil.

Por essa visão, o sentido do aprender e do ensinar na Educação Infantil indica que é preciso "frear a imaginação, a fantasia, controlar o movimento, regular as múltiplas manifestações infantis, uniformizar suas temporalidades, desejos e sonhos" (SIMÃO, 2012, p. 273).

Embora a ideia de criança e de infância pautada na incompletude, cronologicamente situada numa fase da vida em que predomina a preparação 
para a vida que virá depois, no futuro, tenha sido predominante entre os discursos das professoras, foi possível perceber também outros olhares que sinalizam noções mais afirmativas que buscam potencializar as crianças como sujeitos de seu próprio tempo, que valorizam seus diferentes modos de ser, suas infâncias, suas culturas.

Um discurso que, ao que nos parece, indica seguir essa tendência que privilegia a visibilidade das crianças é trazido pela professora P6. Na ocasião da entrevista, ao questionarmos sobre o que caracterizaria os termos criança e infância, a professora enunciou:

Eu acho que uma coisa tá ligada a outra, porque se eu vejo a infância como uma fase do desenvolvimento eu vejo a criança como o ser, o ser da fase, que vive o momento. Veja, eu digo que é fase, mas eu não gosto muito dessa palavra, mas... Vou dizer que é um momento. O momento que a criança mais aprende, se descobre, descobre as coisas que estão ao se redor. Que precisa de muito tempo pra brincar, conversar, desenvolver essa oralidade, de ser ouvido, de ter responsabilidade sim, mas só com as coisas de criança, com seus brinquedos, com suas atividades, isso também é importante pras crianças daqui do CMEI (professora P6, entrevista realizada em 29 de outubro de 2012, grifos nosso).

O fato de destacar que as crianças precisam de "muito tempo para brincar, conversar, ser ouvido" nos sugere que P6, identifica que as rotinas na Educação Infantil precisam ser organizadas de modo a contemplar os diferentes aspectos que ela destaca, ou seja, P6 pelo seu enunciado indica que a criança esteja no foco das ações na Educação Infantil.

Assim como afirma Kramer (2007, p. 15), é preciso reconhecer o que é específico da infância, qual seja "seu poder de imaginação, a fantasia, a criação, a brincadeira entendida como experiência de cultura. Crianças são cidadãs, pessoas detentoras de direitos, que produzem cultura e são nela produzidas".

Essa diversidade de discursos, ao mesmo tempo em que privilegia o sujeito criança a partir de uma idealização, de uma concepção de infância que invisibiliza as crianças, que as adjetiva enquanto falta, imatura, incapaz, aponta para um movimento que busca resistir a essas noções que "negativam" as crianças e suas infâncias e ensaiam novas formas de pensar para além do que já se sabe 
sobre elas, que desloca a posição do olhar sobre a criança e inaugura um olhar para a criança.

Por esse deslocamento, a criança se apresenta para nós como um outro, como o desconhecido, e nesse sentido ela é algo que nos inquieta e tal qual afirma Larrosa (2006, p. 185) esse fato nos inquieta "na medida em que suspende o que podemos (e a arrogância da nossa vontade de poder) e na medida em que coloca em questão os lugares que construímos para ela (e a presunção da nossa vontade de abarcá-la)".

Podemos, nesse sentido, apreender um duplo sentido trazido nos discursos das professoras, acerca da criança e de sua infância. Esses sentidos constituem as rotinas nos CMEI's, o que nos sugere uma Educação Infantil que ora privilegia o controle, a formação, a disciplina, ora promove a descoberta, a brincadeira, as relações.

Tendo por base a estreita relação que há entre crianças e infâncias, contemplaremos a partir de então as discursividades que circularam os enunciados de nossos sujeitos acerca das experiências da infância, em outras palavras, apresentaremos as concepções de infância construídas na experiência das professoras junto às crianças.

Seguramente localizada numa temporalidade, a infância para a professora P1, além da consideração como etapa da vida, está associada a uma série de ações/atividades que só podem ser realizadas nesse período, como podemos acompanhar no trecho que segue.

\footnotetext{
Infância pra mim é você ter a oportunidade de fazer coisas que quando você tiver na fase adulta, você não vai mais fazer. A infância lhe permite fazer sem que seja cobrado algo, entendeu. Sem que você seja considerado imaturo, né. Eu acho que é isso que você tem que vivenciar, é essa fase de coisas que você gostaria de fazer, mas você só pode fazer lá. É você pular, é você correr, é você brincar, é você andar descalço, é você ter a oportunidade de fazer pintura, é você ter a oportunidade de dramatizar, de chorar, de gritar (professora P1, entrevista realizada em 17 de setembro de 2012, grifos nosso).

Embora P1 valorize a infância pelo seu caráter inventivo, pela
} oportunidade de realizar diferentes atividades cuja prioridade ultrapassa a aprendizagem de normas, de memorização e escrita de símbolos, a professora com seu discurso sugere uma delimitação temporal dessas ações infantis. 
Desse modo, o viver a infância está destinado a um tempo determinado, e que, ao se tornar adulto, as possibilidades de exercer essas experiências infantis não existem e, se existirem, os que dela participam são inferiorizados por assumirem tal postura infantil.

Através do discurso de P1, a infância - e tudo que ela considera como característico dessa "fase" - e a criança - sujeito que de acordo com a faixa etária está "autorizado" a vivenciar essa infância - estão, de certo modo, "presos" a uma lógica em que não há outros lugares ou outros sujeitos a ocuparem/vivenciarem as experiências da infância.

Por outro lado, destacamos a discussão feita pela professora P3 ao sinalizar a infância enquanto "modo de vida". Quando questionada sobre o que caracteriza a infância ela enuncia:

Ah, infância é brincar, dançar, cantar pular, correr, é descobrir. E isso num é um período que um dia acaba, tem gente que diz assim "você já tem 10 anos, vamos parar por aqui", pra mim isso não existe não. Infância é modo de vida que a pessoa escolhe ser (professora P3, entrevista realizada em 30 de outubro de 2012, grifo nosso).

Com seu discurso, P3 nos remete as discursividades da Filosofia da Infância que apontam para uma desvinculação da infância com a criança, ou seja, a infância "deixa de estar necessariamente associada a crianças, e a sua visão concomitante como seres humanos pequenos, frágeis, tímidos [...] ela passa a ser [...] experiências de transformações e sentido de metamorfose de qualquer ser humano, sem importar sua idade" (KOHAN, 2003a, p. 246).

Como dissemos anteriormente, as professoras veiculam em seus discursos diferentes modos de conceber as crianças e suas infâncias, por conseguinte, a organização da rotina adquire diversas configurações e prioridades.

Nesse contexto, o dizer, o pensar e o conceber as crianças, as infâncias e a própria Educação Infantil nos contextos dos CMEI's em Caruaru - PE mobilizam discursividades que circulam entre permanências e descontinuidades que de certo modo constituem e redefinem as fronteiras entre a criança, a infância e a vida adulta. 


\section{pontos de chegada e de uma nova partida}

Os discursos analisados, distribuídos em redes discursivas, em linhas gerais, apresentam enunciados e temporalidades para a infância, a criança e a Educação Infantil diversos, mas não excludentes.

Embora em todos os discursos identifique-se uma ampliação da preocupação com o lugar da criança, da infância nas práticas da Educação Infantil, os mesmos revelam tanto indícios de permanência como de mudanças nas formas de dizer a criança, a infância e, consequentemente, a Educação Infantil.

Embora diversos, os discursos, em certa medida, são atravessados por aproximações, distanciamentos, e por que não dizer dilemas, que investem em problematizações cujas ideias enfatizam noções de criança, de infância e de Educação Infantil das quais somos herdeiros e críticos.

Nos enunciados transcritos e analisados, encontramos uma forte vinculação da concepção de infância enquanto etapa da vida marcada pela incompletude, pela falta, com a ideia de que cabe a Educação Infantil preparar, formar essa criança para algo que virá, que acontecerá logo depois dessa fase de transição.

Por outro lado, foi possível identificar também discursividades que apontam para outras perspectivas mais afirmativas, que valorizam a criança naquilo que ela é, reconhecendo a infância enquanto condição, para além de uma fase ou etapa da vida. Desse modo, faz com que os professores organizem as ações na Educação Infantil pautadas na inventividade, no respeito e na interação.

Buscamos, acima de tudo, pela descrição dos enunciados, estabelecer relações entre os discursos, apreender os modos de circulação e produção de sentidos, ou seja, percebermos as mudanças e permanências entre o que nos enunciaram os sujeitos que participaram da investigação, como também entre estes discursos e as discursividades que constituem o campo dos estudos da criança, da infância e de sua educação.

Os dados, portanto, expressam uma diversidade de sentidos e interpretações, mas indicam o quanto a escola e seus sujeitos ainda carecem de uma relação mais afirmativa com a criança e a infância. 
Por fim, tendo como pressuposto a inconclusão que carrega um processo investigativo, tomamos aqui essa condição, não como falha, mas como possibilidade para devires futuros.

\section{referências}

ABRAMOWICZ, A.; LEVCOVITZ, D.; RODRIGUES, T. C. Infâncias em educação infantil. Pro-Posições. Campinas, v. 20, n. 3, p. 179 - 197, Set./Dez. 2009. Disponível em <http:/ / www.scielo.br >. Acesso em 11 de julho de 2012.

ARIÈS, P. História social da criança e da família. Trad. Dora Flaksman. 2. ed. Rio de Janeiro: LTC, 2006.

BEZERRA, A. S.; SALLES, C. G. N. L. A infância na contemporaneidade: enunciados e sentidos entre os professores de educação infantil. In: XV ENDIPE Encontro Nacional de Didática e Prática de Ensino. 2010. Belo Horizonte, MG. Anais Eletrônicos. Disponível em:

http://www.fae.ufmg.br/endipe/publicacoes.php. Acesso em 17 de janeiro de 2012.

CORSARO, W. A. Sociologia da Infância. Tradução: Lia Gabriele Regius Reis. Porto Alegre: Artmed, 2011.

CORSINO, P. Educação infantil: a necessária institucionalização da infância. In: KRAMER, S. Profissionais de educação infantil: gestão e formação. São Paulo: Ática, 2005.

FISCHER, R. M. B. Foucault e a análise do discurso em educação. Cadernos de pesquisa: Revista da Fundação Carlos Chagas. São Paulo, n. 114, p. 197-223, nov., 2001. Disponível em: http://www.scielo.br/pdf/cp/n114/a09n114.pdf. Acesso em 10 de setembro de 2011.

. Foucault revoluciona a pesquisa em educação? Perspectiva, Florianópolis, v. 21, n. 02, p.371 - 389. jul./ dez. 2003. Disponível em:

http://www.perspectiva.ufsc.br/perspectiva_2003_02/07_artigo_rosa_maria.pdf. Acesso em 22 de setembro de 2011.

FOUCAULT, M. A arqueologia do saber. Rio de Janeiro: Forense Universitária, 2009. GHIRALDELLI JR, P. O que é filosofia da educação - uma discussão metafilosófica. In: GHIRALDELLI JR, P. (org.). O que é filosofia da educação. Rio de Janeiro: DP\&A, 2000.

KOHAN, W. O. Infância: entre educação e filosofia. Belo Horizonte: Autêntica, 2003a.

Imagens da infância para (re)pensar o currículo. In: FÓRUM

AMAZÔNICO DE EDUCAÇÃ̃, I. 2003. O Pensamento Brasileiro em Currículo.

Belém, PA, 24 - 26 de outubro, 2003b.

Infância e filosofia. In: SARMENTO, M.; GOUVEIA, M. C. (Orgs.).

Estudos da Infância: educação e práticas sociais. Petrópolis, RJ: Vozes, 2008, Coleção

Ciências Sociais da Educação. 
KRAMER, S. Infância e Educação: o necessário caminho de trabalhar contra a barbárie. In: KRAMER, S. et al. (orgs.). Infância e Educação Infantil. Campinas, SP: Papirus, 1999.

A infância e sua singularidade. In: BEAUCHAMP, J.; PAGEL, S. D.;

NASCIMENTO, A. R. (orgs.). Ensino Fundamental de nove anos: orientações para a inclusão da criança de seis anos de idade. Brasília: MEC/SEB, 2007.

KUHLMANN Jr, M.; FERNANDES, R. Sobre a história da infância. In: FARIA FILHO, L. M. (org.). A infância e sua educação - materiais, práticas e representações. (Portugal e Brasil). Belo Horizonte: Autêntica, 2004.

LARROSA, J. Pedagogia Profana: danças, piruetas e mascaradas. 4. ed. Trad. de Alfredo Veiga-Neto. Belo Horizonte: Autêntica, 2006.

LÜDKE, M.; ANDRÉ, M. E. D. A. Pesquisa em Educação: abordagens qualitativas. São Paulo: EPU, 1986.

PORTO, Z. G. Administração social das crianças e as contribuições da análise de discurso como ferramenta de pesquisa em educação. In: FARIAS, M. S. B.;

WEBER, S. (orgs.). Pesquisas qualitativas nas ciências sociais e na educação: propostas de análise do discurso. João Pessoa: Editora Universitária da UFPB, 2008.

SIMÃO, M. B. A dimensão corporal entre a ordem e o caos: espaços e tempos organizados pelos adultos e pelas crianças. In: ARROYO, M. G.; SILVA, M. R. (orgs.). Corpo Infância: exercícios tensos de ser criança, por outras pedagogias dos corpos. Petrópolis, RJ: Vozes, 2012. 